\title{
The Rubber Tail Illusion as Evidence of Body Ownership in Mice
}

\author{
Makoto Wada, ${ }^{1,2}$ Kouji Takano, ${ }^{1}$ Hiroki Ora, ${ }^{1,3}$ Masakazu Ide, ${ }^{2}$ and Kenji Kansaku ${ }^{1,3}$ \\ ${ }^{1}$ Systems Neuroscience Section and ${ }^{2}$ Developmental Disorders Section, Department of Rehabilitation for Brain Functions, Research Institute of National \\ Rehabilitation Center for Persons with Disabilities, Tokorozawa 359-8555, Japan and ${ }^{3}$ Brain Science Inspired Life Support Research Center, The University \\ of Electro-Communications, Chofu 182-8585, Japan
}

The ownership of one's body parts represents a fundamental aspect of self-consciousness. Accumulating empirical evidence supports the existence of this concept in humans and nonhuman primates, but it is unclear whether nonprimate mammals experience similar feelings. Therefore, the present study used rubber tails to investigate body ownership in rodents. When the real tails and rubber tails were synchronously stroked, the mice responded as if their own tails were touched when the rubber tails were grasped. In contrast, when the stimuli were delivered asynchronously, there was a significantly lower mean response rate when the rubber tail was grasped. These findings suggest that mice may experience body ownership of their tails, suggestive of the rubber hand illusion in humans.

Key words: body ownership; mouse; rubber hand illusion; visuotactile

\section{Significance Statement}

To explore the manner in which the ownership of body parts is experienced, this study specifically used the rubber hand illusion (RHI), in which self-consciousness can be extended out of one's own body. Accumulating empirical evidence supports the existence of this concept in humans and nonhuman primates, but it remains unclear whether nonprimate mammals experience similar feelings. This study demonstrated for the first time that mice may experience body ownership of their tails, which is suggestive of the RHI in humans and provides evidence that may highlight how humans experience the ownership of body parts.

\section{Introduction}

The ownership of one's limbs represents a fundamental aspect of self-consciousness. Under particular conditions, as in the rubber hand illusion (RHI), this feeling can be extended out of one's own body (Botvinick and Cohen, 1998). In the human RHI, when a rubber hand and a participant's hand are synchronously stroked by two brushes, the participant feels that the rubber hand is his or her own. The representation of the body in the brain is thought to be a multisensory construct; thus, visuotactile integration is important for the RHI (Botvinick and Cohen, 1998; Armel and Ramachandran, 2003; Tsakiris and Haggard, 2005).

\footnotetext{
Received Aug. 10, 2015; revised Aug. 24, 2016; accepted Sept. 10, 2016.

Author contributions: H.O. and K.K. designed research; M.W., K.T., and M.I. performed research; K.T. contributed unpublished reagents/analytic tools; M.W. and K.K. analyzed data; M.W. and K.K. wrote the paper.

This study was supported in part the Ministry of Education, Culture, Sports, Science and Technology of Japan, Grants 23300151, 15H03126, and 26700012. We thank T. Ogata, T. Sakurada, T. Nawa, and S. Iwama for their help, and Y. Nakajima for his continuous encouragement.

The authors declare no competing financial interests.

Correspondence should be addressed to Kenji Kansaku, Systems Neuroscience Section, Department of Rehabilitation for Brain Functions, Research Institute of National Rehabilitation Center for Persons with Disabilities, Namiki 4-1, Tokorozawa 359-8555, Japan. E-mail: kansaku-kenji@rehab.go.jp.

DOI:10.1523/JNEUROSCI.3006-15.2016

Copyright $\odot 2016$ the authors $\quad 0270-6474 / 16 / 3611133-05 \$ 15.00 / 0$
}

Nonhuman primate experiments have shown that animals may experience body ownership as well. For example, Iriki et al. (1996) reported that the visual receptive fields of bimodal neurons (somatosensory and vision) in the posterior parietal cortices (PPCs) of monkeys were altered during tool use such that they included the entire length of a rake or covered an expanded accessible space. Similarly, synchronous stimulation applied to a monkey's unseen arm and a fake arm caused changes in the receptive fields of multimodal neurons in the premotor cortex and superior PPC (Graziano, 1999; Graziano et al., 2000). The neural activity within these fields suggests that the body representation of the monkey's limbs extended beyond their own bodies. Likewise, neurons in the sensorimotor cortex were activated by virtual touches to an avatar arm following the synchronous stimulation of the monkey's arm and the avatar arm (Shokur et al., 2013).

In contrast to nonhuman primate studies, no empirical evidence regarding the experience of body ownership in rodents has been reported to date. Therefore, the present study examines whether an RHI-like phenomenon occurs in mice by applying tactile stimulation to rubber tails. Tails are important for locomotion and balance in mice (Siegel, 1970), which suggests that mice may experience body ownership of their tails. In humans, 
RHI-like phenomena occur in a variety of different body parts, including the feet, abdomen, and whole body (Gentile et al., 2015). Therefore, it was hypothesized that this type of illusion could be measured in mice using rubber tails. Real tails and rubber tails were either synchronously or asynchronously stroked, and the responses of the mice (e.g., head movements) were assessed when the rubber tails were grasped. In human and nonhuman primate studies, the motoric defense of the body is a key behavioral indicator of body ownership (Graziano and Cooke, 2006; Ehrsson et al., 2007); thus, the evaluation of defensive withdrawal movements in mice may be a suitable measure of body ownership. Using this procedure, the present experiment provided the first empirical evidence showing that mice may experience body ownership of their tails.

\section{Materials and Methods}

Subjects. The present study included 21 male C57BL6NCrj mice (Charles River Laboratories) that weighed 15-20 g at the beginning of the training period (postnatal week 5). The mice were trained daily to stay in a small tube with their heads stationary. Subsequently, the mice received three to five daily training sessions per week and were provided ad libitum access to water for $>24 \mathrm{~h}$ over each weekend. All mice gained significant weight over the course of the training period. The mice were housed in groups of three to five in a room with a $12 \mathrm{~h} \mathrm{light/dark} \mathrm{cycle;} \mathrm{all} \mathrm{behavioral} \mathrm{exper-}$ iments were conducted during the light cycle. Before the present experiments, the mice had no history of drug administration, surgery, or behavioral testing. The experiments were approved by the institutional committees for animal experimentation (Research Institute of National Rehabilitation Center for Persons with Disabilities).

Apparatus. The mice were trained in a stainless-steel tube specifically designed for the present study (O'Hara). One side of the tube was open, and the other side of the tube was connected to a stainless-steel cone that had windows on the right and left sides. For the experiments, a rubber tail was placed either to the right or left of the cone; because mice can bend their tails forward, the rubber tail was placed in a proper anatomical position. The rubber tail was not placed in an anatomically impossible position because a human study found that an improbable location of a body part far away from the body caused a breakdown of the illusion (Lloyd, 2007; Brozzoli et al., 2012; Kalckert and Ehrsson, 2014).

To prepare the rubber tail, an electric wire coated with red plastic (diameter, $3 \mathrm{~mm}$; length, $10 \mathrm{~cm}$ ) was cut into a conical shape and covered with double-coated adhesive tape. Additionally, small black hair-like particles (Super Million Hair Mini Set; Ruan) were sprayed on the wire. In Experiments 1-3, the rubber tail and the real tail were manually stroked by small flat brushes made of soft sheep hair (width, $7 \mathrm{~mm}$; length, 12 mm; Namura Taiseido; Fig. $1 A$ ).

Task procedures. The basic illusion task consisted of two phases. During phase 1 , the mice $(n=17)$ were trained daily to stay in the small tube with their heads stationary for $20 \mathrm{~min}$. If mice move and the rubber tails do not move in the same way, this inconsistency may weaken the illusion (Kalckert and Ehrsson, 2012). Phase 1 was completed by the majority of mice within 1 month, and the four mice that could not complete the phase were excluded from further analyses. During Phase 2, the tails of the mice and the rubber tails were manually stroked using brushes $(\sim 0.5-2 \mathrm{~Hz})$; the real tails always remained unseen by the mice throughout the experiment. After the rubber tails were stroked for $>1 \mathrm{~min}$, they were strongly grasped by an experimenter and the responses of the mice were recorded.

Three experiments were conducted in the present study. In Experiment 1 , the mice $(n=17)$ performed daily tests under two conditions using a brush: the real tails and rubber tails were synchronously stroked or the real tails and rubber tails were asynchronously stroked. After the tails were stroked for $>1 \mathrm{~min}$, they were grasped by the hand of an experimenter that approached from the front of each mouse with a grasping strength similar to that used by the experimenters when lifting a mouse. The order of conditions was counterbalanced and the responses (head movements) were evaluated using a digital video camera (GZ-G5;
JVCKenwood) that was placed in front of the head. In the asynchronous condition, asynchronous stroking was applied to the real tails and rubber tails with small brushes, as performed previously in the control conditions of human RHI experiments (Botvinick and Cohen, 1998; Armel and Ramachandran, 2003; Ehrsson et al., 2004). In 6 of the 17 mice (mice 12-17), one experimenter who was exposed to white noise over headphones and who could not to see the apparatus during the tactile stimulation firmly grasped the rubber tail after seeing a hand sign from another experimenter who had stroked the real tail or the rubber tail. Thus, the experimenter who grasped the rubber tail was blind to the task conditions.

In Experiment 2, the mice $(n=5)$ performed daily tests under two conditions using small brushes. The stimuli were always administered synchronously; however, in one condition, the rubber tail was occluded by an opaque plastic plate to evaluate the importance of visual stimuli.

In Experiment 3, two rubber tails were prepared and placed to the right and left of the head of each mouse, and one of the rubber tails was stroked synchronously with the real tail. The mice $(n=6)$ performed daily tests under two conditions: the stroked rubber tail was grasped and the nonstroked rubber tail was grasped. After the tails were stroked for $>1 \mathrm{~min}$, an experimenter firmly grasped the rubber tail and the response was recorded.

To minimize the number of animals used in the present study, in some cases the same mice were included in different experiments. Please note that each number in the figures (1-17) indicates an individual mouse.

Data analysis. During the behavioral tasks, the head movements of the mice were recorded using a digital video camera. Head movements in response to the grasping of the rubber tail were evaluated by two technical staff members who were blind to the experimental conditions and the results of these staff members were averaged. If the head promptly faced toward the rubber tail or retracted into the tube, this was considered to be a full response and was scored as 1.0. If the response was small or slightly delayed $(\sim 1 \mathrm{~s})$, this was considered to be an insufficient response and was scored as 0.5 . The findings of the two technical staff members were well correlated $(r=0.82, p<0.01)$. Next, the mean response rates under each condition were calculated from the responses obtained over $10 \mathrm{~d}$ of testing and compared using paired $t$-tests after an assessment for normality with the Kolmogorov-Smirnov test.

\section{Results}

The present study developed an animal model of the RHI to investigate the concept of body ownership in mice. In Experiment 1 , the mice ( $n=17$ ) performed daily tests under two stimulation conditions using a brush: synchronous stroking of real tails and rubber tails and asynchronous stroking of the tails (Fig. $1 A-C)$. After the tails were stroked for $>1 \mathrm{~min}$, an experimenter firmly grasped the rubber tail, and the mean response rate over $10 \mathrm{~d}$ of testing under each condition was recorded. Following synchronous stroking, the mice responded as if their own tails were being touched by turning or retracting their heads when the rubber tails were grasped. Nine of the 17 mice exhibited a significantly higher response rate (mean \pm SEM) under the synchronous stimulation condition $(0.54 \pm 0.0017)$ than under the asynchronous stimulation condition $(0.43 \pm 0.0022$; paired $t$ test, $p=0.00000036<0.000001 ; t_{(16)}=8.27$; Cohen's $d=2.01$; Figure $1 C$ ), which is similar to RHI findings in humans (Armel and Ramachandran, 2003). In 6 of 17 mice, the behavioral tests were assessed by experimenters who were blind to the stimulation conditions (mice 12-17); that is, the experimenters who firmly grasped the rubber tail could not see the apparatus and did not know whether the real tail or the rubber tail had been synchronously stroked. The difference in the response rates between the stimulation conditions was significantly higher for the synchronous stimulation condition $(0.61 \pm 0.044)$ compared with the asynchronous stimulation condition $(0.51 \pm 0.052$; paired $t$ test, $p=0.0062<0.01 ; t_{(5)}=4.53$; Cohen's $\left.d=1.85\right)$. 
A

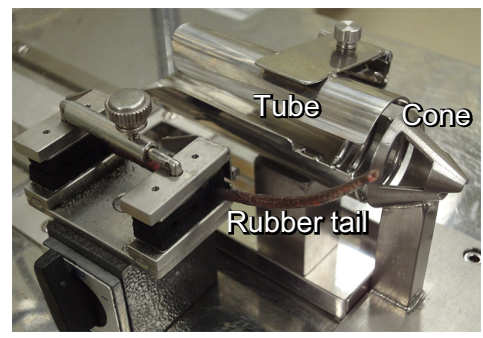

B

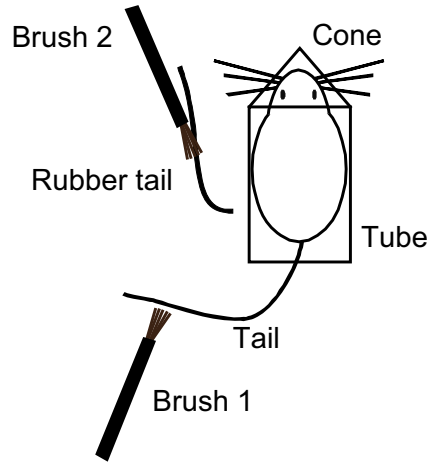

B
Brush 1

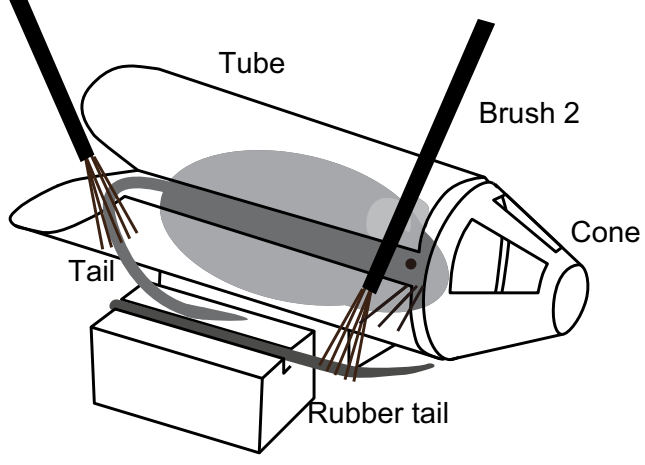

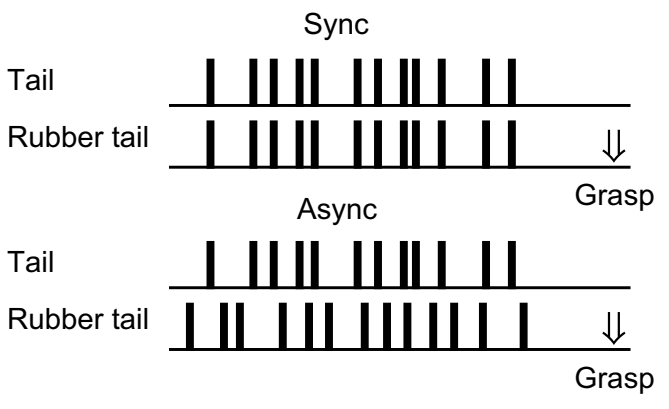

C

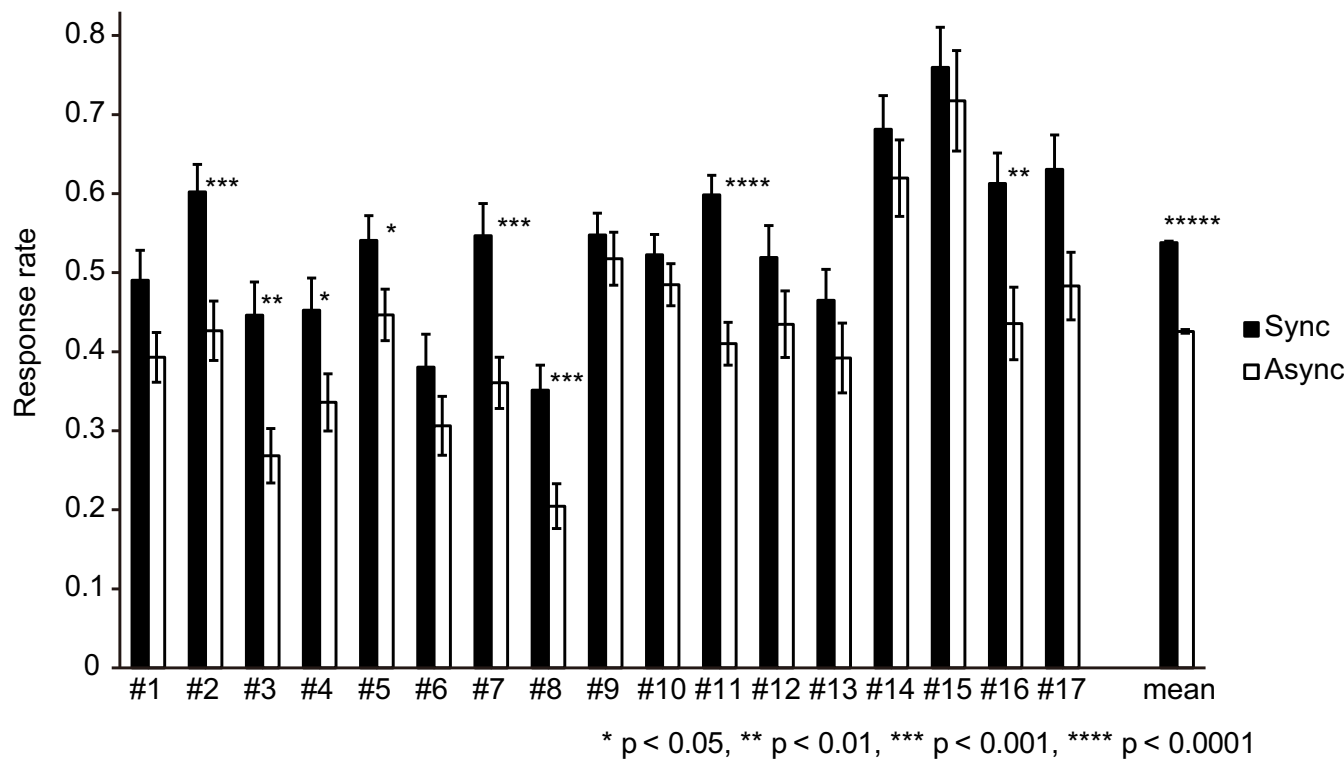

Figure 1. The rubber tail task in mice. A, Picture and illustration of the apparatus. Mice were trained to stay in a stainless-steel tube with a cone that had windows on the left and right sides, and a rubber tail was placed on the left or right side of the cone. $\boldsymbol{B}$, The rubber tail task in Experiment 1 . The mice performed daily tests under two conditions: real tails and rubber tails were stroked synchronously or asynchronously. C, Response rates (head movement) when the rubber tail was grasped. The bars indicate the mean response rate under each condition from the responses obtained over $10 \mathrm{~d}$ of testing (mice 1-17, synchronous condition, $71.7 \pm 6.0$ trials; asynchronous condition, $70.6 \pm 5.5$ trials). Error bars indicate SEM.

Effect of visual occlusion

Experiment 2 assessed the effects of visual occlusion on this RHIlike phenomenon to confirm that the mice saw the rubber tail during the task. As in Experiment 1, the mice $(n=5)$ performed daily tests under two stimulation conditions using a brush: synchronous stroking of real tails and rubber tails and synchronous stroking of real tails and rubber tails with the rubber tail masked by an opaque plastic plate so that it could not be seen (Fig. 2A). 
A
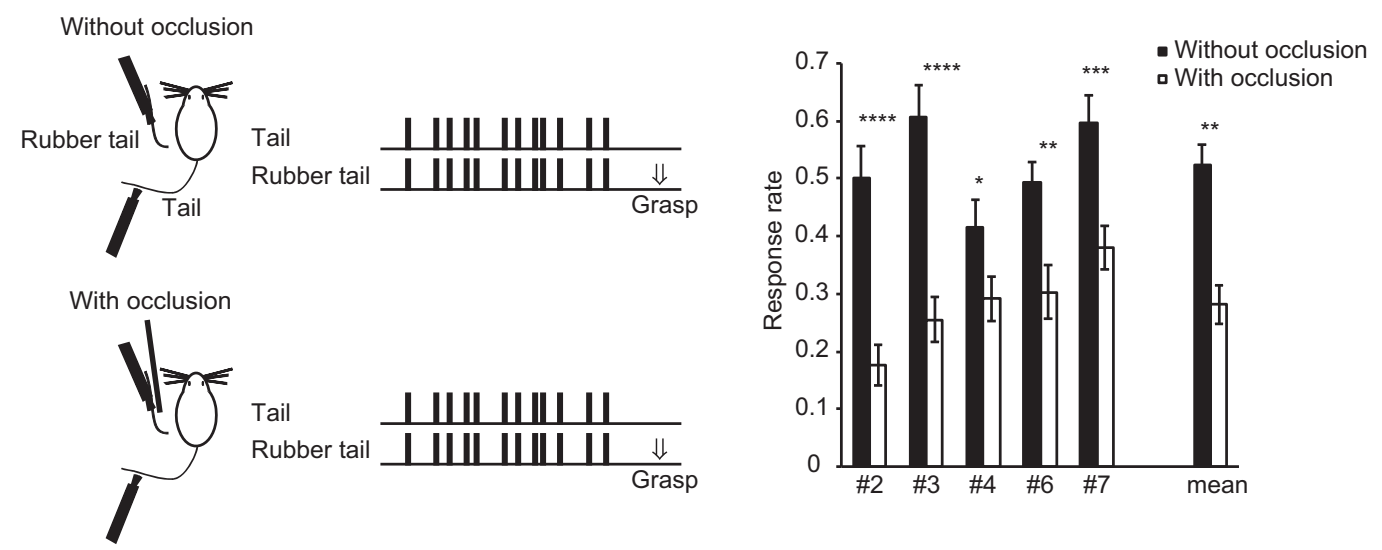

B
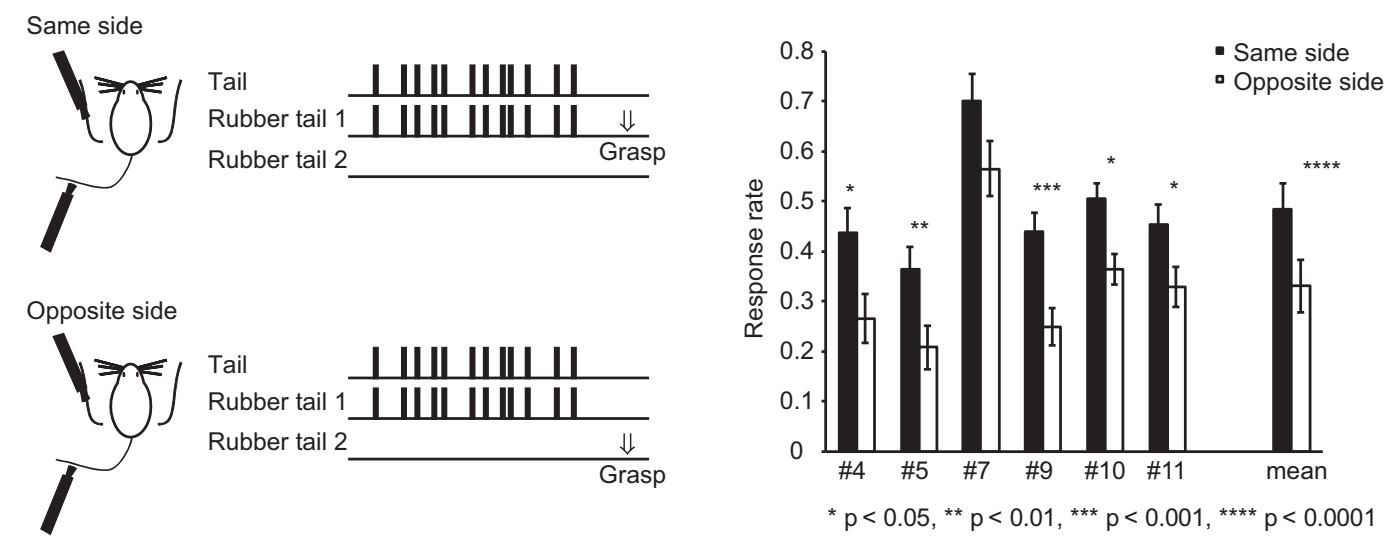

Figure 2. Control experiments. $A$, Effects of visual occlusion (Experiment 2). Mice $(n=5)$ performed daily tests in which the stimuli were always administered synchronously, but under one condition, the rubber tail was occluded by an opaque plastic plate. Response rates of the mice are shown. Bars indicate the mean response rate under each condition from responses obtained over 6 d of testing (mice 2- 4,6,7, without occlusion condition, $46.6 \pm 0.93$ trials; with occlusion condition, $47.2 \pm 1.6$ trials). $\boldsymbol{B}$, Effects of cross-modal spatial congruence (Experiment 3 ). Two rubber tails were placed to the right and left sides of the mice. One of these rubber tails was synchronously stroked along with the real tail. Mice $(n=6)$ performed daily tests under two conditions. Under one condition, the stroked rubber tail was grasped, and under the other, the nonstroked rubber tail was grasped. Mouse response rates are shown (mice 4, 5, 7, 9-11, same side condition, $42.5 \pm 4.7$ trials; opposite side condition, $43.2 \pm 2.1$ trials).

Similar to Experiment 1, if the rubber tail could be seen, then the mice responded as if their own tails were being touched when the rubber tail was grasped $(0.52 \pm 0.035)$. However, when the rubber tail was occluded, the response rate was significantly lower $\left(0.28 \pm 0.033\right.$; paired $t$ test, $p=0.0046<0.01 ; t_{(4)}=5.71$; Cohen's $d=2.55)$. Individual analyses revealed that the response rates of all five mice were significantly lower, suggesting that visuotactile integration was important for the manifestation of the RHI-like phenomenon.

\section{Effect of cross-modal spatial congruence}

Experiment 3 evaluated the influence of spatial location on the RHI-like phenomenon using two rubber tails placed to the right and left sides of the mice (Fig. 2B). The aim of this experiment was to determine whether or not the rubber tail phenomenon was spatially confined. If cross-modal spatial congruency is important (Pavani et al., 2000), then the response should be confined to the side where the synchronous stimuli are applied. The real tails of the mice $(n=6)$ and one of the rubber tails were synchronously stroked, and then the mice performed daily tests under two conditions: one in which the stroked rubber tail was grasped, and one in which the nonstroked rubber tail was grasped. When the stroked rubber tail was grasped, the mice responded as if their own tails were being touched $(0.48 \pm 0.047)$, similar to the synchronous condition in Experiment 1. In contrast, when the nonstroked rubber tail was grasped, there were significantly fewer responses $(0.33 \pm 0.052$; paired $t$ test, $p=0.000021<0.0001$; $t_{(5)}=15.4$; Cohen's $d=6.30$ ). In the individual analyses, this difference remained significant for five of six mice, which suggests that the RHI-like phenomenon was related to cross-modal spatial congruence, as during the RHI in humans.

\section{Discussion}

The present findings from Experiment 1 demonstrate that mice responded as if their own tails were being touched when the rubber tails were grasped after synchronous stroking with two small brushes. The differences between the synchronous and asynchronous conditions suggest that the temporal simultaneity of vision and touch was important for this task. Experiment 2 confirmed the importance of vision during the performance of the illusion, and Experiment 3 demonstrated that the spatial location of the rubber tails influenced the RHI-like phenomenon 
and that spatial attention may be an important consideration during this process. Together, the present behavioral data indicate that mice may experience body ownership of their tails and that the RHI-like phenomena were related to visuotactile integration and spatial congruence.

The present findings are consistent with those of studies investigating the RHI in humans. In the original RHI experiments, watching a rubber hand being stroked while one's own unseen hand is synchronously stroked elicits a feeling that the rubber hand is one's own. In contrast, the asynchronous stimulation of two hands eliminates this illusion (Botvinick and Cohen, 1998). Accordingly, the importance of visuotactile integration and spatial congruence for the perceptual phenomenon of the RHI has been repeatedly reported and discussed (Pavani et al., 2000; Makin et al., 2008; Tsakiris, 2010; Kilteni et al., 2015; Samad et al., 2015).

Functional brain imaging studies in humans have revealed that the ventral premotor cortex and the PPC are activated during the RHI (Ehrsson et al., 2004; Ehrsson et al., 2005). These brain regions are known to be involved in body-related multisensory integration and may coordinate information from various sensory modalities with respect to the RHI (Tsakiris, 2010). Based on the findings of electrophysiological studies, rodents also have a distinct brain region for multisensory processing near the primary sensory cortex (Wallace et al., 2004; Menzel and Barth, 2005). Additionally, Hirokawa et al. (2008) and Wada et al. (2010) reported that the expressions of c-Fos, which is an activity-dependent gene, in these multisensory areas increases after the detection of temporally congruent audiovisual stimuli and temporal order judgments, respectively, in rodents. This multisensory cortex in rodents, which may correspond to the PPC in humans, also represents spatial information (Kesner, 2009). Together, these studies suggest that multisensory brain regions play a role in $\mathrm{RHI}$-like phenomena in mice.

Although empirical studies using rodents have successfully identified the neuronal bases of multisensory processing (Benedetti, 1995; Iurilli et al., 2012; Reig and Silberberg, 2014; Chabrol et al., 2015), the cognitive aspects of body representation in rodents have yet to be fully examined. The present findings suggest that mice may experience body ownership of their tails; therefore, the task used in this study may be applicable for the evaluation of the cognitive aspects of body representations in mice. Future research using this behavioral task may provide novel insights into the ownership of one's body parts.

\section{References}

Armel KC, Ramachandran VS (2003) Projecting sensations to external objects: evidence from skin conductance response. Proc Biol Sci 270:14991506. CrossRef Medline

Benedetti F (1995) Orienting behaviour and superior colliculus sensory representations in mice with the vibrissae bent into the contralateral hemispace. Eur J Neurosci 7:1512-1519. CrossRef Medline

Botvinick M, Cohen J (1998) Rubber hands 'feel' touch that eyes see. Nature 391:756. CrossRef Medline

Brozzoli C, Gentile G, Ehrsson HH (2012) That's near my hand! Parietal and premotor coding of hand-centered space contributes to localization and self-attribution of the hand. J Neurosci 32:14573-14582. CrossRef Medline

Chabrol FP, Arenz A, Wiechert MT, Margrie TW, DiGregorio DA (2015) Synaptic diversity enables temporal coding of coincident multisensory inputs in single neurons. Nat Neurosci 18:718-727. CrossRef Medline

Ehrsson HH, Spence C, Passingham RE (2004) That's my hand! Activity in premotor cortex reflects feeling of ownership of a limb. Science 305:875877. CrossRef Medline

Ehrsson HH, Holmes NP, Passingham RE (2005) Touching a rubber hand:
Feeling of body ownership is associated with activity in multisensory brain areas. J Neurosci 25:10564-10573. CrossRef Medline

Ehrsson HH, Wiech K, Weiskopf N, Dolan RJ, Passingham RE (2007) Threatening a rubber hand that you feel is yours elicits a cortical anxiety response. Proc Natl Acad Sci U S A 104:9828-9833. CrossRef Medline

Gentile G, Björnsdotter M, Petkova VI, Abdulkarim Z, Ehrsson HH (2015) Patterns of neural activity in the human ventral premotor cortex reflect a whole-body multisensory percept. Neuroimage 109:328-340. CrossRef Medline

Graziano MS (1999) Where is my arm? The relative role of vision and proprioception in the neuronal representation of limb position. Proc Natl Acad Sci U S A 96:10418-10421. CrossRef Medline

Graziano MS, Cooke DF (2006) Parieto-frontal interactions, personal space, and defensive behavior. Neuropsychologia 44:845-859. CrossRef Medline

Graziano MS, Cooke DF, Taylor CS (2000) Coding the location of the arm by sight. Science 290:1782-1786. CrossRef Medline

Hirokawa J, Bosch M, Sakata S, Sakurai Y, Yamamori T (2008) Functional role of the secondary visual cortex in multisensory facilitation in rats. Neuroscience 153:1402-1417. CrossRef Medline

Iriki A, Tanaka M, Iwamura Y (1996) Coding of modified body schema during tool use by macaque postcentral neurones. Neuroreport 7:23252330. CrossRef Medline

Iurilli G, Ghezzi D, Olcese U, Lassi G, Nazzaro C, Tonini R, Tucci V, Benfenati F, Medini P (2012) Sound-driven synaptic inhibition in primary visual cortex. Neuron 73:814-828. CrossRef Medline

Kalckert A, Ehrsson HH (2012) Moving a rubber hand that feels like your own: a dissociation of ownership and agency. Front Hum Neurosci 6:40. Medline

Kalckert A, Ehrsson HH (2014) The spatial distance rule in the moving and classical rubber hand illusions. Conscious Cogn 30:118-132. CrossRef Medline

Kesner RP (2009) The posterior parietal cortex and long-term memory representation of spatial information. Neurobiol Learn Mem 91:197-206. CrossRef Medline

Kilteni K, Maselli A, Kording KP, Slater M (2015) Over my fake body: body ownership illusions for studying the multisensory basis of own-body perception. Front Hum Neurosci 9:141. Medline

Lloyd DM (2007) Spatial limits on referred touch to an alien limb may reflect boundaries of visuo-tactile peripersonal space surrounding the hand. Brain Cogn 64:104-109. CrossRef Medline

Makin TR, Holmes NP, Ehrsson HH (2008) On the other hand: Dummy hands and peripersonal space. Behav Brain Res 191:1-10. CrossRef Medline

Menzel RR, Barth DS (2005) Multisensory and secondary somatosensory cortex in the rat. Cereb Cortex 15:1690-1696. CrossRef Medline

Pavani F, Spence C, Driver J (2000) Visual capture of touch: Out-of-thebody experiences with rubber gloves. Psychol Sci 11:353-359. CrossRef Medline

Reig R, Silberberg G (2014) Multisensory integration in the mouse striatum. Neuron 83:1200-1212. CrossRef Medline

Samad M, Chung AJ, Shams L (2015) Perception of body ownership is driven by Bayesian sensory inference. PLoS One 10:e0117178. CrossRef Medline

Shokur S, O’Doherty JE, Winans JA, Bleuler H, Lebedev MA, Nicolelis MA (2013) Expanding the primate body schema in sensorimotor cortex by virtual touches of an avatar. Proc Natl Acad Sci U S A 110:15121-15126. CrossRef Medline

Siegel M (1970) The tail, locomotion and balance in mice. Am J Phys Anthropol 33:101-102. CrossRef

Tsakiris M (2010) My body in the brain: A neurocognitive model of bodyownership. Neuropsychologia 48:703-712. CrossRef Medline

Tsakiris M, Haggard P (2005) The rubber hand illusion revisited: visuotactile integration and self-attribution. J Exp Psychol Hum Percept Perform 31:80-91. CrossRef Medline

Wada M, Higo N, Moizumi S, Kitazawa S (2010) c-Fos expression during temporal order judgment in mice. PLoS One 5:e10483. CrossRef Medline

Wallace MT, Ramachandran R, Stein BE (2004) A revised view of sensory cortical parcellation. Proc Natl Acad Sci U S A 101:2167-2172. CrossRef Medline 